\title{
LIMITES, POSSIBILIDADES E DESAFIOS NO PROCESSO DE GESTÃO E PARTICIPAÇÃO DAS IFES/UFT
}

\author{
Roberto Francisco de Carvalho*
}

Recebido: 28 nov. 2011

Aprovado: 23 maio 2012

* Doutor em Educação pela Universidade Federal de Goiás (2007-2011). Professor adjunto I da Universidade Federal do Tocantins (UFT) / Campus Universitário de Miracema, atuando na área de Política Educacional: disciplinas políticas públicas e gestão da educação e planejamento e gestão da educação. Palmas, TO, Brasil. E-mail:carvalho1917@gmail.com

Resumo: Neste artigo buscamos explicitar a compreensão de participação na gestão da UFT conforme estudo realizado envolvendo os documentos institucionais e a percepção da comunidade universitária. A discussão acerca da participação na gestão da UFT teve como ponto de partida o entendimento do processo de regulação social resultante da imbricação das esferas pública e privada e das abordagens liberal e histórico-materialista de democracia. Neste sentido, tem sido fortalecida a esfera privada mercantil em detrimento da pública evidenciando-se a mercantilização da educação superior e suas características de natureza neoprofissional, heterônoma, competitiva e operacional. Assim, têm sido fortalecidos nas IFES/UFT os valores da democracia liberal/neoliberal minimalista, operacionalizados na lógica da gestão e da participação estratégico-empresarial. Nesta lógica, os obstáculos à participação no processo de gestão da UFT não diferem dos obstáculos à participação na sociedade de uma forma geral, e têm a ver com o modo de organização e efetivação do sistema de produção e reprodução social capitalista.

Palavras-Chave: Esfera Privado-mercantil. Democracia. Gestão/Participação nas IFES/UFT.

\section{LIMITS, POSSIBILITIES AND CHALENGES IN THE PROCESS \\ OF MANAGEMENT AND PARTICIPATION OF THE IFES/UFT}

Abstract: This article aims to clarify the understanding of participation in the UFT management according to a study of institutional documents and of the perception of the university community. The discussion about the participation in the UFT management had as starting point the understanding of the social regulation process and the intertwining of the public and private spheres and the liberal and historical-materialist approaches of democracy. In this way the mercantile private sphere has been strengthened in detriment of the public, evidencing the marketization of college education and its neoprofessional nature, heteronomous, competitive and operational characteristics. So, the liberal/neoliberal minimalist democracy values have been strengthened in the IFES/UFT, operationalized in the management logic and the business-strategic participation. In this logic, the barriers to the participation in the UFT management process do not differ from the society participation in general, and is related with the organizational mode and the enforcement of the capitalist production and reproduction system.

Key words: Mercantile-private sphere. Democracy. IFES/UFT management/participation.

\section{INTRODUÇÃO}

No presente artigo $^{1}$ discutimos a participação nas Instituições Federais de Educação Superior (IFES) tomando como base empírica específica o processo

1 O presente artigo toma por base as reflexões feitas na tese "O processo de gestão e participação na universidade: limites, possibilidades e desafios na UFT" defendida em junho de 2011, na Faculdade de Educação da Universidade Federal de Goiás (UFG). 
de gestão e participação na Universidade Federal do Tocantins (UFT) conforme os documentos institucionais e a percepção da comunidade universitária: docentes, discentes e técnico-administrativos em educação (TAE) ${ }^{2}$. Buscamos, neste sentido, responder que tipo de gestão se efetiva na UFT e como ocorre a participação em tal processo, sem desconsiderar a participação na sociedade e nas IFES brasileiras. Objetivando responder a esta questão estabelecemos como objetivo geral compreender - considerando as demais IFES - a participação no processo de gestão da UFT.

A participação no processo de gestão da universidade pública brasileira nesse início de século XXI constitui-se uma problemática de múltiplas determinações endógenas e exógenas. Tais determinações condicionam as políticas públicas educacionais e afetam a participação dos membros da comunidade universitária. Frente ao exposto, dentre outros aspectos, justificaram a realização do presente estudo: as mudanças que vêm ocorrendo desde 1990 no campo das ciências, nos modelos de Estado e de produção que têm impactado no processo de gestão das instituições sociais como as universidades; a existência de acanhados estudos sobre a gestão das universidades públicas brasileiras; o reconhecimento da existência de dificuldades no processo de gestão das IFES no atual contexto educacional brasileiro e de poucos estudos que dão conta delas; e a problematização da tensão entre a importância ou não de se ampliar a participação, em geral, dos segmentos da comunidade universitária no processo de gestão das IFES, especialmente na UFT, no sentido de, também, ampliar a sua autonomia e democratização para além da democracia representativa minimalista de viés burocrático e regulatório-regulamentatório.

A temática acerca da participação é atual e tem significados distintos no âmbito da sociedade capitalista em geral e, em particular, das organizações empresariais e instituições sociais, de acordo com os processos implementados: fabril, político-social, administrativo, entre outros. Tomando o caso da universidade pública brasileira, em especial as IFES, a participação, em geral, faz parte das preocupações da comunidade universitária, mas tem sentidos diferentes conforme os interesses envolvidos: gestores, entidades representativas, cientistas e estudiosos da área.

Em geral, vários estudos têm-se ocupado da problemática da gestão e da participação na universidade. Alguns deles, devido à natureza do trabalho educativo, têm retratado a temática da participação como uma dimensão técnica de

2 A sigla TAE (técnico-administrativo em educação) no presente texto refere-se ao conjunto dos técnicoadministrativos da UFT que abrange, além dos cargos técnico-administrativos educacionais, os demais técnicos: médicos, psicólogos, engenheiros, advogados, arquitetos, bibliotecários, assistentes sociais, administradores etc. 
engajamento limitada à função que cada segmento da comunidade universitária exerce. Outros estudos problematizam a temática da participação como forma de ampliação do processo democrático na sociedade em geral e, em particular, em suas instituições; por este motivo, defendem uma participação efetiva da comunidade universitária nos espaços de deliberação e nos processos de tomadas de decisão em geral. Inseriu-se na tensão entre a possibilidade de ampliação ou não da participação a temática referente ao processo de gestão e participação na UFT, tal como previsto nos documentos institucionais e conforme a percepção da comunidade universitária.

No estudo que dá sustentação a este artigo utilizamos a abordagem do materialismo histórico-dialético como método de pesquisa, buscando apreender o objeto de estudo e desvelar suas múltiplas determinações (MARX, 1982). Neste sentido, considerando o processo de modernização do Estado brasileiro e suas implicações para a democratização e participação nas IFES, realizamos uma investigação de natureza teórico-empírica, incluindo levantamento bibliográfico, pesquisa documental e de campo abrangendo um total de 812 sujeitos da comunidade universitária dos sete campi da UFT. Na pesquisa de campo foi utilizada como técnica de pesquisa o questionário ${ }^{3}$ destinado aos professores, estudantes e técnico-administrativos além de observação sistematizada junto ao Conselho Universitário, Conselho de Ensino, Pesquisa e Extensão, e Conselhos Diretores.

\section{AMPLIAÇÃO DA ESFERA PRIVADO-MERCANTIL, MODERNIZAÇÃO DO ESTADO BRASILEIRO E A DEMOCRATIZAÇÃO DA GESTÃO DAS IFES E UFT}

O estudo acerca da participação na gestão da UFT teve como ponto de partida o entendimento do processo de regulação social, resultante: do imbricamento das esferas pública, na perspectiva do bem comum e do interesse geral da sociedade, e privada mercantil, na perspectiva do bem particular e do interesse econômico dos indivíduos isoladamente (MÉSZÁROS, 2004); e das abordagens de democracia liberal, fundamento da participação representativa minimalista (SCHUMPETER, 1961) e histórico-materialista que vislumbra a participação política efetiva nos processo de tomadas de decisões (GRAMSCI, 1978). A partir dessa discussão explicitamos a tensão entre as perspectivas

3 Da amostra selecionada para a pesquisa, totalizando 1.372 sujeitos (sendo 319 professores, 750 estudantes e 303 TAE) o estudo abrangeu um total de 812 (59\%) dos sujeitos selecionados. Os participantes que responderam os questionários ficaram distribuídos da seguinte forma: $149(47 \%)$ professores, $504(67 \%)$ estudantes e 159 (52\%) TAE (CARVALHO, 2011, p. 235). 
estratégico-empresarial e democrático-participativa de gestão e participação nas organizações empresariais e instituições sociais como as IFES/UFT. Frente a tal perspectiva de regulação social procuramos compreender a participação na modernização do Estado brasileiro e no seu bojo a democratização da universidade pública brasileira com destaque para a participação da comunidade universitária na sua gestão, em momentos distintos (FÁVERO, 1980).

Buscamos, neste sentido, aprofundar a discussão sobre o momento em que tem se explicitado o poder do mercado e das organizações sociais, tensionado pelo Estado - 1990 a 2010 -, no qual tem sido fortalecida a esfera privada mercantil em detrimento da pública e evidenciado o processo de mercantilização da educação superior explicitando, no âmbito das IFES, as características de natureza neoprofissional, heterônoma, competitiva e operacional (SGUISSARDI, 2004; CHAUÍ, 1999). Ou seja, uma universidade focada nas profissões que dão dinâmica à competição do mercado, administrada na perspectiva empresarial e desprovida de autonomia. Neste contexto, tem sido fortalecida nas IFES e na UFT a democracia liberal/neoliberal minimalista operacionalizada na lógica da gestão e participação estratégico-empresarial (CONTERA, 2002; CATANI; OLIVEIRA; DOURADO, 2004). Este é, também, o contexto em que buscamos compreender a participação no processo de gestão da UFT, uma universidade que, em princípio, apresenta uma estrutura - organizada em conselhos e colegiados com a representação dos segmentos da comunidade universitária favorável à participação democrático-participativa, mas que implementa uma gestão muito próxima da gerencial na qual nem mesmo a participação liberal representativa se consolidou.

O processo de modernização do Estado brasileiro, orientado pelos valores liberais tomados em sua historicidade e tendo como manifestação recente o neoliberalismo como expressão política e ideológica, constituiu-se o ponto de partida para a discussão acerca da democratização da universidade pública brasileira (CHAUÍ, 2001). Tal processo foi analisado dentro de uma compreensão ampliada de Estado, que possibilitou o entendimento da sociedade a partir da imbricação, no seio da superestrutura, da sociedade política com a sociedade civil. A partir desse entendimento, a educação foi compreendida como parte constitutiva e constituinte do universo das relações sociais mais amplas, consistindo, assim, num campo importante de disputa do poder e construção de hegemonia pelas classes sociais fundamentais (COUTINHO, 2007; CARDOSO, 1977).

A modernização do Estado brasileiro trouxe implicações para o histórico processo de democratização e participação na universidade pública, mas, tam- 
bém, a relação da universidade com a sociedade, com o conhecimento e com o poder implicou tal processo modernizador. A universidade é perpassada por relações externas e internas de poder expresso em acirradas disputas, conforme o interesse, por espaços de participação. Tal disputa, muitas vezes, é escamoteada pela intensificação e precarização do trabalho, pela estrutura organizacional da instituição, que inclui os conselhos e colegiados, e pela perspectiva de gestão e participação adotada.

Tomando como referência Fávero $(1980 ; 1983)$, a relação de poder na universidade brasileira tem estreito vínculo com a relação de poder na sociedade, pois, ao mesmo tempo em que a universidade exerce a função de reprodutora das relações sociais de produção constitui-se em espaço que, ao produzir conhecimento e reflexões críticas, influencia as transformações sociais. Preponderantemente é a sociedade que modifica a universidade, mas a sociedade só se modifica enquanto suas instâncias, dentre as quais as universidades, também se modificam. Os acontecimentos estruturais de uma sociedade acabam por determinar os rumos de suas instituições e, ao mesmo tempo, são influenciados por estas, em conformidade com o poder dos sujeitos sociais nos processo de tomada de decisão.

Nesse sentido, o entendimento da participação na universidade pública, principalmente nas IFES, passa pela compreensão da forma como o poder historicamente tem-se estruturado no seu interior e como a autonomia e a democratização aí se constituíram. Assim, abordamos, no presente estudo, o poder do mercado e das organizações sociais tensionado pelo Estado, buscando compreender a participação no processo de gestão das IFES/UFT.

Nessa direção, apreendemos a forma de organização administrativa das IFES e a participação no seu processo de gestão tomando como categorias orientadoras a autonomia e a democratização universitárias. Historicamente, no entender de Fávero $(2000 ; 2006)$, a organização da universidade pública brasileira tem sido reestruturada e reformada conforme as forças político-sociais em movimento. Essas forças, extrínseca e intrinsecamente mobilizadas, têm impactado a universidade. Externamente, devido à pressão de organismos multilaterais e da sociedade em geral, a universidade é pressionada pelos governos, que tensionam o seu processo de autonomia. Internamente, o que provoca as alterações são as forças mobilizadas na disputa por uma organização institucional mais ou menos propícia à participação e à democratização, ou seja, na relação de poder que resulta em uma gestão tensionada entre verticalização e horizontalização do poder decisório, tendo, dentre outros, os conselhos e colegiados como espaços formais de tomada de decisão. 
Tomando como referência a história da universidade brasileira, particularmente a das IFES, e o conjunto da legislação educacional, a despeito da luta dos segmentos da universidade e da sociedade, ainda persistem, em grande medida, as dificuldades para o avanço da autonomia e da gestão democrática com efetiva participação dos segmentos da comunidade universitária. Essa realidade, dentre outras questões, tem a ver com as dificuldades de democratização da própria sociedade. Por outro lado, embora as barreiras à participação política insistam em permanecer, muito já se avançou e esses avanços não são dádivas, nem partem da vontade ou do interesse governamental, mas resultam da luta e persistência dos sujeitos sociais que buscam a autonomia, a liberdade e a emancipação cidadã nos diversos processos sociais. A universidade constitui-se um dos espaços onde ocorre essa luta: uma luta entre diferentes projetos educativos.

O contexto social mais amplo em que se situa a problemática da participação nas IFES, incluindo a UFT, orienta-se por um processo sócio-histórico no qual se evidenciam os valores liberais/ neoliberais como liberdade, igualdade de oportunidade, propriedade, democracia representativa e individualismo. Faz parte de tal lógica a defesa da despolitização dos mercados e da liberdade absoluta da circulação dos indivíduos e dos capitais privados; a valorização do individualismo em detrimento do coletivismo; e a promessa de igualdade de oportunidades independente da igualdade de condições e da classe social a que se pertença.

A dinâmica neoliberal tem sido operacionalizada por meio da escamoteação da dimensão política em aspectos de natureza técnica. Particularmente na área da educação, essa dinâmica se efetiva por meio da transformação das questões de ordem políticosociais em questões de natureza técnico-instrumentais. Ocorre, assim, a exaltação dos aspectos de ordem técnica em detrimento dos aspectos de ordem política, que traz consequências para a participação no seu sentido efetivo, pois, participar, nessa lógica, em instituições educativas, por exemplo, como na gestão das IFES, tem a ver muito mais com iniciativas individuais diárias focadas na denominada flexibilidade, multifuncionalidade e compartilhamento requeridos no mundo da produção capitalista e envolve, em grande medida, as dimensões técnico-pedagógicas, científicas, técnico-administrativas e econômicas (SANDER, 1995). O discurso da participação tem o sentido do agir individual na definição dos objetivos e métodos educacionais operacionais transmitindo a sensação de democracia, escolha e participação.

Em tal perspectiva de participação, administradas sob a lógica do mercado, as universidades, especialmente as IFES, passaram também a sofrer pressão para 
submeter-se à lógica gerencial operacionalizada por controles burocráticos dos resultados, em uma perspectiva de administração competitiva. Nesse sentido, na década de 1990, o governo brasileiro optou por uma administração pública gerencial de natureza estratégico-empresarial visando melhorar o desempenho governamental e os serviços prestados.

A perspectiva de gestão gerencial de natureza estratégico-empresarial adotada tem grande proximidade com aquela praticada no setor privado e o planejamento estratégico foi a forma proposta para se conseguir a eficiência sistêmica na lógica das "organizações sociais" (OS) que integram o Programa Nacional de Publicização (PNP). Nessa perspectiva de gestão, a participação, no que se refere às finalidades institucionais, dá-se praticamente no nível do compartilhamento da informação, no sentido de conscientizar os servidores em geral da missão institucional e dos resultados globais desejados, de forma a identificar qual é o espaço de sua contribuição individual, para que esses resultados sejam alcançados a partir do planejamento estratégico. Não é difícil perceber aqui o processo de separação entre os que pensam a instituição, ligados à alta administração, e os situados no nível da execução do que já fora planejado, ou seja, a maioria dos trabalhadores da instituição (BRASIL, 1998, p. 13).

No contexto da reforma da educação e, em seu bojo, na gestão da educação superior, evidencia-se a gestão gerencial de natureza estratégico-empresarial à qual é reduzido o leque dos envolvidos com as tomadas de decisão no processo educativo e ampliado o dos que são convocados a participar da execução do que foi decidido externamente, no âmbito da burocracia estatal. Esse tipo de participação coaduna-se com o que vem ocorrendo no âmbito de muitas das instituições de educação superior, como as IFES, por exemplo, no quesito planejamento estratégico.

No âmbito da reforma do Estado e da educação, outra preocupação, da década de 1990 e recorrente na primeira década do século XXI, tem sido o controle das IFES por meio do contrato de gestão. O contrato de gestão nos moldes inicialmente propostos nos anos de 1990 não chegou a se concretizar, mas as IFES têm sido pressionadas, desde então, a se adequarem à lógica mercadológica das organizações sociais, a exemplo da recente alternativa de gestão dos Hospitais Universitários via organizações da sociedade civil de interesse público, com base nas parcerias público-privadas e no contrato de gestão no âmbito do REUNI (LÉDA; MANCEBO, 2009). Esta lógica tem trazido, progressivamente, consequências para a educação superior pública, em especial para a autonomia e o processo de gestão democrática, sustentada na efetiva participação da comunidade universitária. 
Por essa via de entendimento, a concepção de universidade evidenciada desde meados da década de 1990, sem desconsiderar os atenuantes e agravantes, tem seus desdobramentos na primeira década do século XXI com a ampliação, no âmbito do Estado, da esfera privada mercantil em detrimento da pública, tendo como expressão a explicitação das relações mercantis na universidade a partir, por exemplo, da prestação de serviços ao mercado por meio de fundo público ou não, objetivando à captação de recursos. Nesse cenário, efetiva-se a lógica da universidade estatal pública, que se mercantiliza com base na institucionalização dos serviços não-exclusivos do Estado e termina por produzir um trabalhador dotado de nova sociabilidade produtiva (SGUISSARDI; SILVA JUNIOR, 2009). Tal produtivismo tende a acirrar o individualismo e a competitividade no interior da universidade pública, exemplificado pelo que ocorre nas IFES, em especial na UFT, e evidencia uma perspectiva de prática educativa cada vez mais pragmática e utilitarista em contraste com uma perspectiva mais emancipatória, autônoma e democrática na qual os interesses coletivos, o bem comum e a participação efetiva sejam priorizados no processo de gestão universitária.

Nessa lógica, tem, também, acirrado o individualismo e a competição por recursos extraorçamentários, por exemplo, para complementação salarial. Essa forma de agir no âmbito das IFES, principalmente por parte de professores, tem enfraquecido o engajamento político-sindical e arrefecido a participação na vida institucional em geral, possibilitando certa centralização, em órgãos administrativos, do processo de tomada de decisão. A participação na lógica dessa nova sociabilidade produtiva fortalece mais os vínculos extrainstitucionais do que a participação institucional (SGUISSARDI; SILVA JUNIOR, 2009).

$\mathrm{Na}$ medida em que se intensifica a lógica econômico-mercantilista na universidade, a efetiva participação na reflexão, no debate e na maturação da compreensão da realidade institucional, encontra fortes dificuldades. Assim, a esfera pública, o bem comum e o interesse coletivo em geral, defendido, dentre outros, por Rousseau (2006), Gramsci (2006) e Coutinho (2007), são fortemente invadidos pela esfera privada mercantil e pelos interesses particulares, dentro de uma nova sociabilidade competitiva de orientação liberal/neoliberal fundada em uma perspectiva de democracia liberal representativa de viés minimalista. Entretanto, dessa mesma realidade na qual se intensificam as contradições do sistema capitalista afloram sinais de resistência, acadêmica, sindical, trabalhista, entre outras, que, embora pareçam frágeis, precisam ser considerados como alentadores do revigoramento da dimensão política no processo de produção e reprodução da vida social, inclusive nas IFES (CARVALHO, 2011). 
Esse mesmo ambiente institucional das IFES, às vezes considerado pouco participativo em virtude das suas múltiplas determinações, também comporta um processo de disputa que envolve os segmentos da comunidade universitária por maior participação nos espaços formais e não formais de tomadas de decisão. Em âmbito nacional, e com desdobramento em cada IFES, dentre elas a UFT, a luta por democratização e maior participação na gestão universitária é protagonizada por entidades representativas como o Sindicato Nacional dos Docentes das Instituições de Ensino Superior (Andes-SN), a União Nacional dos Estudantes (UNE) e a Federação de Sindicatos de Trabalhadores em Educação das Universidades Brasileiras (Fasubra).

\section{GESTÃO E PARTICIPAÇÃO NA UFT: CONTRADIÇÕES ENTRE A CENTRALIZAÇÃO E A DESCENTRALIZAÇÃO DO PODER DE DECISÃO}

Nesse contexto contraditório de continuidade e ruptura no processo de gestão das IFES, encontra-se a UFT, que, em princípio, parece ser administrada na perspectiva da gestão democrático-participativa, em virtude de suas características gerais como: estrutura universitária multicampi; eleição de Diretor de Campus, Coordenador de Curso, Reitor; existência de Conselhos e Colegiados na administração central e nos Campi, dentre outros. À primeira vista, há um processo de gestão que assegura efetiva participação da comunidade acadêmica no seu processo de gestão. Entretanto, por meio da análise dos dados referentes ao presente estudo, pôde ser desvelado que ocorre na UFT, de fato, uma gestão de perspectiva regulatórioregulamentatória de natureza estratégico-empresarial, própria das organizações empresariais, apresentada como democrática e viabilizada por meio da estruturação e participação em Conselhos e Colegiados, bem como na escolha de dirigentes institucionais.

Tendo em vista as informações documentais referentes às IFES que compuseram o referido estudo como ilustração, a UFRGS, UFF, UFC, UFG e UFAM, os dados da pesquisa revelaram como ocorre, na UFT, a distribuição percentual de participantes no Conselho Universitário (Consuni) e no Conselho de Ensino, Pesquisa e Extensão (Consepe) e como se efetiva o processo de participação na escolha dos dirigentes universitários, como o reitor, o vice-reitor, os diretores de campi, de centro, de unidades e os coordenadores de cursos e departamentos (CARVALHO, 2011).

Quanto à distribuição dos participantes no Consuni, considerando-se os grupos de dirigentes institucionais; representantes de centros, campus, unidades, 
departamentos, cursos, câmaras; representante da comunidade externa; representante docente; representante discente; e representante TAE, é ilustrativo destacar o fato de os dirigentes institucionais, reitor, vice-reitor, diretores e pró-reitores, corresponderem a um percentual entre $40 \%$ (UFRGS) e $63 \%$ (UFG) do total de participantes; a existência de representantes de centros, campi, unidades, departamentos, cursos e câmaras em quatro IFES, UFRGS, UFF, UFC e UFG; a existência de participantes da comunidade externa, variando entre $4 \%$ e $6 \%$ do total, nas cinco IFES estudadas; e a prevalência, na composição do Consuni, em primeiro lugar, de docentes, seguidos dos discentes e TAE. Na UFT, embora o número de representantes entre os segmentos docente, discente e TAE seja equivalente (10\%), o número de dirigentes institucionais (70\%) que participam do Consuni, em relação aos demais grupos, é superior ao quantitativo relativo das cinco IFES pesquisadas. Acrescente-se a isso o fato de, na composição do Consuni, inexistirem representantes de outros espaços da universidade e de segmentos da comunidade externa diferindo do que ocorre nas outras IFES (CARVALHO, 2011).

Referindo-se ao Consepe/ UFT, a partir dos dados apresentados, ficou evidenciado que o número dos dirigentes da instituição também é preponderante em relação aos segmentos docente, discente e TAE, tendo em vista que a somatória dos dirigentes que compõem a gestão superior (14\%) e dos coordenadores de cursos $(77 \%$ ) chega a $91 \%$ dos membros desse conselho. Assim, a composição desse conselho distancia-se um pouco mais daquela dos conselhos das IFES mencionadas anteriormente. É possível dizer, pois, que na UFT a desigualdade na relação de participação entre os representantes da comunidade universitária e os dirigentes da instituição é bem maior e se distancia ainda mais do que as entidades representativas, como o Andes-SN, a UNE e a Fasubra defendem: uma participação paritária (CARVALHO, 2011).

Em parte, esta relação ocorre em virtude da forma como administrativamente a UFT está estruturada, tendo em vista que os cursos de graduação e pós-graduação stricto sensu têm uma relação direta com a administração superior por meio dos seus coordenadores, que têm assento nato no Consepe. Pode ser que essa forma de composição contribua para acentuar a desigualdade no processo de participação, mas essa estruturação por si só não é suficiente para explicar o aprofundamento dessa desigualdade. Referindo-se à ilustração das IFES mencionadas é possível organizar a composição dos conselhos superiores de outras formas, como por exemplo, por campus ou por área do conhecimento. A representação dos segmentos docente, discente e TAE pode, por esse caminho, ser ampliada no sentido de proporcionar uma participação mais representativa 
da comunidade universitária nas tomadas de decisão no âmbito da UFT no que compete ao Consepe.

Quanto à distribuição percentual dos segmentos docentes, discentes e TAE na escolha dos dirigentes institucionais, como Reitor, Vice-Reitor, Diretores, Coordenadores de Cursos e Chefes de Departamento, os dados extraídos dos documentos institucionais demonstraram que, nas IFES pesquisadas, assim como na UFT, o processo de escolha de tais dirigentes ocorre na forma da Lei $\mathrm{n}^{\circ}$ 9.192/1995 e do Decreto Lei 1.916/1996. Em conformidade com a norma, nos Estatutos e Regimentos das IFES, feita a consulta à comunidade universitária, elabora-se, nos órgãos colegiados, uma lista tríplice indicando nomes aos cargos mencionados para a nomeação pelas autoridades competentes. Os segmentos docente e discente/TAE participam desigualmente da consulta na proporção percentual de $70 \%$ e $30 \%$ respectivamente, além do que a validação dos resultados das consultas à comunidade universitária é, normalmente, feita nos órgãos colegiados (CARVALHO, 2011).

No que se refere à composição dos conselhos superiores Consuni e Consepe, há uma alta concentração de poder dos dirigentes institucionais em relação aos demais grupos de participantes e no tocante à escolha dos dirigentes universitários, o poder de decisão dos professores em relação aos segmentos discentes e TAE é muito maior. Essa realidade revela que mesmo a perspectiva de participação na lógica da democracia representativa na UFT ainda não se consolidou. A composição dos conselhos e a escolha de dirigentes na UFT evidenciam que há espaço para a ampliação numérica de participação dos representantes dos segmentos docentes, discentes e TAE no processo de gestão da instituição, mas, para além dos conselhos e escolhas de dirigentes, a participação pode ser ampliada para os diversos espaços e atividades no âmbito da universidade. Essa perspectiva de democracia efetivamente participativa - na acepção gramsciana - vislumbra um processo educativo que busque a construção de relações menos desiguais entre dirigentes e dirigidos. No caso do processo de gestão da UFT, a ampliação da democratização, além de outros aspectos, relaciona-se à diminuição da desigualdade, tanto na composição dos espaços formais de participação quanto na escolha dos dirigentes (CARVALHO, 2011).

Ressaltamos que, na abordagem de democracia efetivamente participativa, é preciso esgotar os limites da democracia representativa viabilizando a gestão coparticipativa como estratégia que vislumbre frentes de lutas e trilhas possíveis rumo à ampliação da autonomia na gestão universitária. Adotar a gestão coparticipativa implica, dentre outras coisas, a ampliação dos espaços de participação e a equalização, dentro das regras do jogo democrático repre- 
sentativo, das oportunidades para os segmentos da comunidade universitária atuarem como sujeitos e corporações autônomos. Ressaltamos, com base no pensamento gramsciano, que o exercício da participação se constitui como ponto de partida para esses mesmos sujeitos para, além da corporação, imbuírem-se da construção de um projeto coletivo de universidade, fundamentado na noção de bem comum e no interesse público (GRAMSCI, 2006).

São várias as possibilidades de influenciar tal processo educativo, dentre as quais destacamos a participação dos professores, estudantes e TAE tanto na elaboração de planos, projetos, programas, na formulação de políticas, quanto na execução de tais ações e na própria avaliação dos resultados. O foco da luta, nesse sentido, é a democratização da gestão institucional, que pressupõe, entre outros aspectos, a constante construção da autonomia; a ampla participação nas tomadas de decisão; a transparência administrativa por meio da democratização das informações sobre, por exemplo, o funcionamento administrativo, o orçamento e as leis. Em suma, a luta deve envolver os sujeitos da comunidade universitária para que, sem desconsiderar os valores individuais, participem das tomadas de decisão coletivas, para além da democracia representativa nos conselhos e colegiados.

\section{A PARTICIPAÇÃO NA GESTÃO DA UFT: PERCEPÇÃO DA COMUNIDADE UNIVERSITÁRIA}

Os dados da pesquisa de campo acerca da participação no processo de gestão da UFT, na percepção dos segmentos da comunidade universitária, revelaram, em geral, que esse processo é, de fato, bastante desigual, principalmente entre, de um lado, os professores e, de outro, os estudantes e TAE. Também demonstrou que, embora haja uma luta dos segmentos da comunidade universitária por ampliação da participação nos espaços de tomadas de decisão, contraditoriamente, os representantes desses mesmos segmentos estiveram ausentes de parte significativa das reuniões dos conselhos e colegiados e no desenvolvimento de diversas atividades importantes no âmbito da UFT. Os dados também explicitaram que a contradição nesse processo de participação está relacionada aos obstáculos à participação na sociedade em seu sentido amplo, que têm, na lógica da universidade neoprofissional, heterônoma, competitiva (SGUISSARDI, 2004) e operacional (CHAUÍ, 1999), obstaculizado a participação no processo de gestão institucional. Tal lógica está diretamente relacionada ao processo de ampliação da esfera privada mercantil e da democracia liberal/neoliberal representativa (GRAMSCI, 1978; MÉSZÁROS, 2004) de viés minimalista no 
âmbito das IFES, em particular da UFT, que se coaduna com uma perspectiva de gestão estratégico-empresarial na qual ocorre uma participação tutelada e limitante (CONTERA, 2002; CATANI; OLIVEIRA; DOURADO, 2004).

Em geral, na visão dos professores, os princípios da gestão democrática estão, em parte, presentes no processo de gestão da UFT, pois no desenvolvimento das ações internas à universidade tem havido respeito ao pluralismo de ideias, participação nas tomadas de decisão, transparência e autonomia. Embora, de certa forma concordando com os professores, os estudantes e TAE entendem que não existe ainda satisfatória igualdade de oportunidade e de condições no desenvolvimento das ações da UFT e que falta mais empenho dos gestores no sentido de prestar contas à comunidade universitária.

Os dados da pesquisa revelaram que a gestão da UFT é caracterizadamente múltipla e que existe, em seu processo, certa tendência, respectivamente, nos Conselho Superiores/ Diretores e nos Colegiados de Cursos, de discutir e deliberar mais sobre os pontos de pauta voltados para os aspectos econômico-administrativos - que envolvem recursos financeiros e materiais, estruturas, normas burocráticas e mecanismos de coordenação e comunicação $(66 \%)$ e $(60 \%)$ e pedagógicocientíficos - relativos ao conjunto de princípios, cenários e técnicas educacionais (25\%) e (33\%). No que tange ao aspecto político, que engloba as estratégias de ação organizadas dos participantes do sistema educacional e cultural, envolvendo os valores e as características filosóficas, antropológicas, biopsíquicas e sociais as discussões e deliberações foram de (9\%) e (7\%) (CARVALHO, 2011).

Decorrente de tal tendência no processo de deliberação, a participação na UFT ocorre, tendencialmente, no nível da execução de ações, secundarizando os níveis da definição das políticas e diretrizes institucionais, do planejamento e da avaliação. Essa tendência de participação relaciona-se a um conjunto de fatores e, no caso da UFT, tem a ver, dentre outros, com: o fato de a universidade estar em fase de consolidação; as determinações concorrenciais e mercadológicas provenientes das mudanças que vêm ocorrendo no âmbito do Estado, com seus efeitos na precarização e intensificação do trabalho na universidade; e, decorrente dessas determinações, a perspectiva estratégico-empresarial de gestão adotada, o que contribui para nortear a perspectiva de participação institucional.

Os dados da pesquisa explicitaram, com base na percepção da comunidade universitária, que a participação desta em aspectos gerais não se efetiva numa perspectiva mais igualitária entre os segmentos que a compõem. No âmbito do segmento docente, embora a participação não seja efetiva, há sinais de ocorrer uma participação numericamente maior, pois os professores têm melhor in- 
fluenciado em alguns aspectos do processo de gestão da UFT, como elaboração e execução de planos, programas e projetos. Já a participação dos estudantes e TAE não tem possibilitado a estes segmentos influenciar efetivamente nas decisões no âmbito dos Conselhos Superiores, como o Consuni e Consepe, e no que se refere à tomada de decisões no plano da formulação das diretrizes, planejamento e avaliação institucionais. Dessa forma, é possível dizer que a participação dos segmentos estudantil e dos TAE se dá, em grande medida, no processo de execução das ações.

As respostas dos participantes da pesquisa não indicam a realização de uma gestão que envolva de forma efetiva os sujeitos da comunidade universitária, particularmente estudantes e TAE, nos espaços deliberativos, por meio dos seus representantes e, ao mesmo tempo, avance em direção a uma democracia participativa, abrangendo, em seu sentido amplo, o conjunto das ações em desenvolvimento na instituição. Neste sentido, os dados revelaram que, para os três segmentos, a participação na definição das diretrizes institucionais e na alocação e administração dos recursos ainda não ocorre efetivamente.

São evidências da afirmação anterior o fato de $73 \%$ dos professores responderem que não participaram do estabelecimento de estratégias macro-institucionais com vistas à elaboração dos planos, programas e projetos da UFT; da alocação de recursos e administração de recursos financeiros (76\%); e da avaliação dos resultados dos planos, programas, projetos, atividades e ações diversas no processo educativo em geral (55\%) (CARVALHO, 2011).

Nessa mesma direção, a maioria dos estudantes e TAE sinaliza que suas participações na gestão da UFT ocorre, predominantemente, na execução de ações ligadas aos planos, programas e projetos em desenvolvimento no âmbito da universidade. Em outras palavras, esses dois segmentos, estudantes e TAE, respectivamente, não têm participado do estabelecimento das diretrizes gerais da instituição (88\%) e (87\%), do macroplanejamento institucional (86\%) e (75\%), da elaboração dos seus principais documentos, programas e projetos $(83 \%)$ e (75\%), da alocação e administração de recursos (87\%) e (79\%) e da avaliação da produção universitária (78\%) e (80\%) (CARVALHO, 2011).

Corroboram os dados anteriores o fato de que os estudantes e TAE, respectivamente, não participaram, no âmbito da UFT, do processo de elaboração do Planejamento Estratégico da UFT (95\%) e (91\%); do Plano de Desenvolvimento Institucional (96\%) e (96\%); do Plano Pedagógico Institucional (96\%) e (98\%); do acompanhamento da aplicação do orçamento da universidade (93\%) e (74\%); do Projeto Político Pedagógico (91\%) e (92\%); e das Resoluções, normativas etc. pertinentes ao segmento (89\%) e (71\%) (CARVALHO, 2011). 
Mesmo tendo uma percepção mais positiva sobre o processo de participação os professores expuseram aspectos que os desmotivam a participar da gestão da UFT, dentre os quais se destacam a falta de profissionalismo, o centralismo, o clientelismo e o excesso de atividades laborais, impostas sem muita discussão. Para os estudantes, além da falta de oportunidade de participação, são, também, fatores que os desmotivam a participar o precário processo de comunicação das ações do próprio segmento; a carga horária de trabalho e estudo; a discriminação por parte de gestores e professores; a inabilidade administrativa dos gestores; e as atividades diretamente ligadas ao curso. Segundo os TAE, as oportunidades de participação na gestão da UFT não são muitas. Mencionaram como desencorajadores da participação, além da falta de oportunidades, traços que caracterizam discriminação, o clientelismo e a centralização das decisões na figura dos gestores e professores.

Tendo como referência a discussão realizada anteriormente, o ambiente universitário, embora em escala menor, reproduz o processo de divisão e de desigualdade que ocorre na sociedade. Nessa linha de raciocínio, evidenciam-se os condicionantes da participação, que têm a ver com aspectos internos e externos à universidade, ligados ao processo de tomada de decisão em que estão implicados, de forma articulada e conflitante, os interesses públicos e privados (MÉSZÁROS, 2004). O ambiente universitário, no caso da UFT, embora com sua especificidade e no qual os professores, estudantes e TAE desenvolvem funções também específicas, está submetido à mesma lógica de produção e reprodução da vida na sociedade em geral. Nesse espaço educativo subsistem, paradoxalmente, ao lado de interesses econômico-mercantis e do desenvolvimento de funções individuais específicas, os interesses voltados para o bem comum (GRAMSCI, 2004, v. 2, Q. 12, § 3), que requerem, portanto, para sua realização formas de participação coletivas, menos fragmentadas e centralizadas no processo de gestão institucional.

Os dados da pesquisa em pauta explicitaram que a participação da comunidade universitária nas tomadas de decisão importantes do processo de gestão da UFT ainda está aquém do almejado na perspectiva de gestão democrático-participativa, especialmente no que se refere aos segmentos dos estudantes e a dos TAE. Há, por parte dos três segmentos, apetência por uma maior participação e melhor representação nos conselhos e colegiados, visto que há indícios de concentração de participação na figura de gestores e dos representantes que não vêm promovendo, satisfatoriamente, a discussão com os representados. Tal constatação sugere que, também na UFT, persiste o problema da democracia representativa de viés minimalista. 
Acerca da participação dos segmentos da comunidade universitária - por meio dos seus representantes nas reuniões do Consuni, Consepe e Conselhos Diretores pesquisados - ficou evidenciado que o segmento discente foi o menos frequente $(36 \%)$ enquanto a presença de professores $(88 \%)$ e TAE $(92 \%)$ foi significativa. Tendo como fonte de pesquisa as atas de 21 cursos de graduação da UFT no ano de 2007, no âmbito dos colegiados desses cursos, foi constatado que os TAE participaram, como conselheiros, em somente dois dos 21 cursos pesquisados, ou seja, nos 19 demais colegiados de cursos os técnicos não foram incluídos como conselheiros. Nos dois colegiados em que os TAE tiveram a oportunidade de participar como conselheiros o total de comparecimento às reuniões perfez $33 \%$ de frequência. Do conjunto dos professores previstos a participarem como conselheiros das reuniões dos colegiados de cursos, $69 \%$ estiveram presentes. Nessas mesmas reuniões a participação dos estudantes, como conselheiros, foi numericamente baixa (31\%) em relação ao quantitativo de estudantes que poderiam participar. Do conjunto das reuniões de que os estudantes poderiam participar como conselheiros, estes deixaram de comparecer a 52\%, o que reforça a afirmação de baixa participação do segmento estudantil nos colegiados de cursos (CARVALHO, 2011).

O estudo demonstrou, nesse sentido, a existência de um paradoxo relativo à participação da comunidade universitária no processo de gestão da UFT, pois, de um lado, verifica-se uma demanda por participação nos processos de tomada de decisão nos diversos espaços participativos e, por outro lado, observa-se uma baixa participação nesses mesmos espaços, em atividades e ações importantes que vêm ocorrendo na universidade, principalmente, no que se refere ao nível da proposição e elaboração de diretrizes e planos. Há a reivindicação por maior participação, mas nem mesmo os espaços de deliberação existentes estão sendo preenchidos, particularmente, por estudantes e TAE. Os dados da pesquisa revelaram que os segmentos da comunidade universitária querem participar, entretanto, as condições almejadas para tal participação foram levantadas pelo presente estudo somente enquanto perspectiva, isto é, são apontados apenas alguns indicativos a esse respeito. Assim, a não realização de uma participação efetiva tem múltiplas explicações, que abrangem, dentre outros aspectos: a natureza multicampi da UFT; a estruturação organizacional da universidade em forma de conselhos e colegiados, mas que não viabiliza a participação da comunidade universitária; a pertinência da participação no processo de gestão para os professores, estudantes e TAE; e a inconsistência do processo de representação no âmbito da universidade.

Em geral, podemos dizer que os obstáculos à participação no processo de ges- 
tão da UFT, embora em escala menor, não diferem dos obstáculos à participação na sociedade e têm a ver com o modo como o sistema de produção e reprodução social está organizado tendo em vista os entraves de ordem econômico-material, ideológico-cultural, político, institucional e comunicacional que se interpõem a essa participação (CARVALHO, 2011).

A efetivação da participação em uma concepção gramsciana depende, em determinada medida, de como essa participação se efetiva na sociedade, mas a microparticipação na universidade pode servir como importante espaço de aprendizado para a macroparticipação. Um bom começo, entendendo-se a educação como prática social situada no campo ideológico e da esfera superestrutural, é, certamente, o de se ter consciência de como a universidade é gerada e desenvolvida e de como os sujeitos que a produzem estão organizados e se relacionam para tal produção. Um segundo aspecto é entender que essa produção se dá por meio da disputa por projetos educativos diferentes e, nesse sentido, as forças políticas no interior da universidade se movimentam para sustentar tais projetos utilizando-se de uma determinada concepção de gestão e de participação.

A pesquisa indicou a existência de uma gestão regulatório-regulamentatória de natureza estratégico-empresarial na UFT, na qual há uma alta desigualdade de participação nos espaços decisórios. Tal desigualdade de participação se expressa na grande distância entre gestores e docentes, que atuam mais intensamente, e os outros dois segmentos: discentes e TAE. Acrescente-se a isso, conforme participantes da pesquisa, que o processo de gestão na UFT carece de ações mais transparentes, coletivas e dialógicas que privilegiem o pluralismo solidário. Isso significa combater, dentre outros aspectos, as atitudes de tendência centralizadora, autoritárias, individualistas, particularistas e preconceituosas.

A superação dos entraves que limitam a participação, como é revelado pelos dados da pesquisa, somente ocorrerá com a emergência de um projeto democrático-participativo de gestão universitária que privilegie maior igualdade de oportunidades e de condições de participação no âmbito da comunidade universitária. Ressalta-se que este projeto somente será possível por meio da superação dialética da realidade dada. Conforme Gramsci (2007, v. 3, Q. 7, p. 262) e Coutinho (2007), é do embate político teóricoprático, que articule "guerra de movimento" e "guerra de posição"4 tendo em vista a proposta de universidade em movimento, que será possível, ou não, construir-se um novo

4 No plano político, a "guerra de movimento" refere-se à tomada de poder formal radical e frontal por meio da conquista da sociedade política ou aparelho político-administrativo. Já a "guerra de posição" trata-se da conquista estratégica do poder por meio da formação do consenso no interior da sociedade civil como ponto de partida para a construção hegemônica no âmbito do Estado ampliado (COUTINHO, 2007). 
projeto comprometido em sustentar outra forma de organização e gestão universitária, que tenha como propósito a participação efetiva, englobando os níveis da tomada de decisão, execução e avaliação dos processos educativos.

Para superar a gestão em vigência na UFT, os participantes da pesquisa elencaram um conjunto de propostas, que abrangem os princípios democráticos; os aspectos político-administrativos e pedagógicos; os aspectos comunicacionais; os aspectos político-organizacionais e corporativos; os aspectos ideológico-culturais e os aspectos materiais e econômicos. Estes aspectos constituem campo fértil de discussão e indicam possibilidades prognósticas importantes no que se refere à participação no processo de gestão da UFT.

\section{CONSIDERAÇÕES FINAIS}

Frente às reflexões realizadas anteriormente, o estudo mencionado, em geral, contribuiu para explicitar a crescente ampliação da esfera privada mercantil que tem influenciado o papel do Estado, da educação e da universidade como, por exemplo, no que se refere à relação de poder, à gestão e à participação no processo de tomada de decisões. Especificamente, a pesquisa possibilitou diagnosticar, a partir dos documentos institucionais e da percepção da comunidade universitária, o processo de gestão e participação na UFT, revelando uma forte concentração de poder nos dirigentes institucionais e na figura de professores, bem como uma participação não efetiva no desenvolvimento das ações e atividades institucionais.

Tendo sido explicitadas as revelações da presente pesquisa, não podemos deixar de indicar as dificuldades e limites de estudos desta natureza, bem como apontar alguns aspectos que precisam ser aprofundados em investigações posteriores, com a finalidade de ampliar o leque de significados a respeito da temática da participação no processo de gestão das IFES e, em especial, da UFT.

Dentre as dificuldades e limites do estudo podemos destacar a impossibilidade de aprofundamento acerca da concepção de universidade e gestão em desenvolvimento na UFT, por meio de uma investigação detalhada das práticas de gestão diversas, que envolvem os conselhos e outros espaços de participação; da relação entre o processo de reestruturação produtiva da sociedade capitalista, a nova sociabilidade produtiva, o empreendedorismo empresarial e a participação no processo de participação na gestão das IFES, em especial da UFT; do tipo de relação estabelecida entre o Ministério do Planejamento, o MEC, o CNPq, CAPES e as IFES e as implicações de tal relação para a participação no processo de gestão da UFT; do aprofundamento no que se refere aos impactos do 
processo de precarização por meio, por exemplo, da terceirização dos serviços, e intensificação do trabalho para a participação na gestão da UFT; da forma organizativa das entidades representativas dos professores, dos estudantes, dos TAE e o papel desempenhado por essas entidades no processo de gestão e participação da UFT; e das implicações da estrutura universitária multicampi na participação no processo de gestão da UFT.

Reconhecendo a dinâmica do processo de gestão das universidades públicas, entendemos, nesse sentido, que, para o aprofundamento da temática acerca da participação nas IFES e, em particular, na UFT, faz-se necessário continuar investigando, em geral, as múltiplas determinações do agir humano frente às constantes mudanças que vêm ocorrendo no processo de produção e reprodução da vida em sociedade na lógica do capital, tomando como materialidade específica: as instituições sociais como as universidades públicas brasileiras; a relação de poder no âmbito da sociedade e das universidades públicas brasileiras a exemplo das IFES, em especial da UFT; a centralidade do trabalho educativo no âmbito da universidade, levando em consideração a natureza, o interesse, o papel e a finalidade dos segmentos da comunidade universitária; bem como a concepção de gestão das IFES, em especial da UFT, e suas implicações para o processo formativo em suas dimensões técnico-científica e político-cultural na percepção do público-alvo.

De modo específico, coloca-se como desafio a futuros estudos apreender o amálgama político-cultural em constituição no âmbito da UFT, expresso, dentre outros aspectos, por meio: da regulamentação institucional, referente ao processo de gestão e participação como derivada do ordenamento jurídico nacional; da história institucional que abrange a origem, a forma de produção institucional em geral, o perfil dos membros da comunidade universitária, os valores e interesses em disputa; da organização específica, referindo-se às finalidades, estrutura organizacional e processo de gestão; e da centralidade das atividades fim em relação às atividades meio da universidade, incluindo o conflito entre os interesses burocráticos e profissionais e a adequação das decisões ao processo de gestão institucional.

Nessa perspectiva, entendemos que os condicionantes da participação são múltiplos e não estão circunscritos ao âmbito institucional, mas tem com ele um vínculo profundo, explicitado na forma de organização e de gestão. Nessa compreensão de gestão, a dimensão política constitui-se em elemento chave que pode mobilizar os sujeitos envolvidos no processo educativo, seja para a manutenção de uma lógica de participação limitante, seja para a superação da alienação em favor de maior controle por parte da maioria dos integrantes da 
comunidade universitária sobre o processo de tomada de decisão nos espaços institucionais.

Nessa linha de raciocínio, o que está em jogo é a disputa pelo poder no âmbito da universidade, e, dessa forma, a efetivação da participação, ou não, consiste em estratégias para a manutenção, ou não, do poder. A ampliação ou a diminuição da participação e da democracia efetiva estão relacionadas aos projetos de sociedade, de educação e de gestão hegemônicos assumidos. O projeto de sociedade é encaminhado em função das lutas travadas pelas principais forças sociais - lutas de classes - e tem implicação nos rumos que a sociedade segue; se na perspectiva de ampliação da esfera pública, do bem comum e do interesse geral da sociedade ou na perspectiva da esfera privada mercantil, do bem particular e do interesse dos indivíduos isoladamente. O projeto de educação e de universidade não prescinde desse projeto geral e relaciona-se com um processo de gestão fruto da tensão entre as perspectivas estratégicoempresarial e democrático-participativa.

Nessa perspectiva, pensando-se a universidade como campo de disputa por hegemonia, situada no âmbito da esfera superestrutural, a luta pela ampliação da esfera pública, da democracia e da gestão democrático-participativa implica uma luta da comunidade universitária pela efetiva participação, também nas IFES, como é o caso da UFT. Tal luta fundamenta-se, necessariamente, nos princípios democráticos: descentralização, transparência, autonomia, diálogo, pluralismo de ideias e participação como ação política organizada. Em sentido amplo, essa luta abrange o combate à política produtivo-mercantilista induzida pelo governo, principalmente via Capes, CNPq e pelo setor produtivo. No âmbito da UFT, sem perder de vista as demais IFES, a luta compreende, entre outros aspectos, o embate para diminuir a desigualdade de participação nos espaços formais de tomada de decisão e na escolha dos dirigentes, bem como para ampliar a participação para os diversos espaços e atividades no processo de gestão institucional.

\section{REFERÊNCIAS}

BRASIL. MINISTÉRIO DA ADMINISTRAÇÃO FEDERAL E REFORMA DO ESTADO. Organizações Sociais. Brasília-DF: Ministério da Administração Federal e Reforma do Estado (MARE), 1998. Caderno 2. 
CONTERA, Cristina. Modelos de avaliação da qualidade da educação superior. In.: SOBRINHO, José Dias; RISTOFF, Dilvo I (Org.). Avaliação democrática: para uma universidade cidadã. Florianópolis: Insular, 2002. p. 119-144.

COUTINHO, Carlos Nelson. Gramsci: um estudo sobre o seu pensamento político. Rio de Janeiro: Civilização Brasileira, 2007.

CARVALHO, Roberto Francisco de. O processo de gestão e participação na universidade: limites, possibilidades e desafios na UFT. 2011. $350 \mathrm{f}$. Tese (Doutorado em Educação) - Universidade Federal de Goiás, Goiânia, 2011.

CARDOSO, Miriam Limoeiro. Ideologia do desenvolvimento - Brasil: JK JQ. Rio de Janeiro: Paz e Terra, 1977.

CATANI, Afrânio Mendes; OLIVEIRA, João Ferreira de; DOURADO, Luiz Fernandes. As políticas de gestão e de avaliação acadêmica no contexto da reforma de educação superior. In.: MANCEBO, Deise; FÁVERO, Maria de Lourdes Albuquerque. Universidade: políticas, avaliação e trabalho docente. São Paulo: Cortez, 2004. p. 251-262.

CHAUÍ, Marilena de Souza. A universidade operacional. Folha de S. Paulo, São Paulo, p. 3, 9 maio 1999.

. Escritos sobre a universidade. São Paulo: UNESP, 2001.

FÁVERO, Maria de Lourdes. Universidade \& poder: análise crítica/ fundamentos históricos: 1930-1945. Rio de janeiro: Achiamé, 1980.

. Universidade: poder e participação. Educação e Sociedade, São Paulo, v. 5, n. 16, p. 42-61, dez, 1983.

. Universidade do Brasil: das origens à construção. Rio de Janeiro: Editora UFRJ/ INEP, 2000.

. UDF: Construção criadora e extinção autoritária. In.: MOROSINI, Marília (Org.). Universidade no Brasil: concepções e modelos. Brasília; DF: INEP, 2006. p. 53-70.

GRAMSCI, Antonio. Maquiavel, a política e o estado moderno. 3. ed. Trad.: Luiz Mário Gazaneo. Rio de janeiro: Civilização Brasileira, 1978. 
GRAMSCI, Antonio. Cadernos do Cárcere v. 1/ Antonio Gramsci. 4. ed. Trad.: Carlos Nelson Coutinho et al. Rio de Janeiro: Civilização Brasileira, 2006.

. Cadernos do Cárcere v. 2/ Antonio Gramsci. 3. ed. Trad.: Carlos Nelson Coutinho et al. Rio de Janeiro: Civilização Brasileira, 2004.

Cadernos do Cárcere v.3/ Antonio Gramsci. 3. ed. Trad.: Carlos Nelson Coutinho et al. Rio de Janeiro: Civilização Brasileira, 2007.

LÉDA, Denise Bessa; MANCEBO, Deise. REUNI: heteronomia e precarização do trabalho docente. Educação e Realidade, Porto Alegre, v. 34, n. 1, p. 49-64, jan/abr., 2009.

MARX, Karl. Para a critica da economia política: salário, preço e lucro; o rendimento e suas fontes: a economia vulgar. Trad. Edgard Malagodi et al. São Paulo: Abril Cultural, 1982.

MÉSZAROS, Istvám. O poder da ideologia. Trad.: Paulo Cezar Castanheira. São Paulo: Boitempo, 2004.

ROUSSEAU, Jean-Jaques. O contrato social. Trad. Ciro Mioranza. São Paulo: Editora Escala, 2006.

SANDER, Benno. Gestão da educação na América Latina: construção e reconstrução do conhecimento. Campinas: Autores Associados, 1995.

SCHUMPETER, Joseph A. Capitalismo, socialismo e democracia. Rio de Janeiro: Fundo de Cultura, 1961.

SGUISSARDI, Valdemar. A universidade neoprofissional, heterônoma e competitiva. In.: MANCEBO, Deise; FÁVERO, Maria de Lourdes Albuquerque. Universidade: políticas, avaliação e trabalho docente. São Paulo: Cortez, 2004. p. 33-52.

; SILVA JUNIOR, João dos Reis. Trabalho intensificado nas

federais: pós-graduação e produtivismo acadêmico. São Paulo: Xamã, 2009. 